\title{
Efficiency improvement with intelligent control of induction motor drives
}

\author{
R. Mecke \\ Department of Automation and Computer Sciences \\ Harz University of Applied Sciences \\ Friedrichstraße 57-59, D-38855 Wernigerode (Germany) \\ Phone/Fax number:+49 3943659 831, e-mail: rmecke@ hs-harz.de
}

\begin{abstract}
The energy saving potential of induction motor drives is investigated. Two new aspects are identified, a multilevel frequency inverter and the speed control with variable rotor flux. Multilevel inverters with new wide-bandgap semiconductors for low voltage electrical drives $(<1000 \mathrm{~V})$ reduce power semiconductor losses, voltage transients at the motor windings and harmonic losses in the cables. The power semiconductor losses of a two-level and a three-level inverter are compared. At $20 \mathrm{kHz}$ switching frequency the losses of the threelevel inverter are $38 \%$ lower compared to the two-level inverter. Another efficiency improvement potential is the speed control with variable rotor flux instead of commonly used constant flux. The rotor flux for maximum efficiency depends on the actual load and speed of the motor. The optimal rotor flux for maximum motor efficiency can be pre-calculated for each load and speed and implemented as reference value for rotor flux control in the frequency inverter. The maximum efficiency improvement with an $11 \mathrm{~kW}$ induction motor at small load reaches $35 \%$ in motor and $45 \%$ in generator operation mode. An increase in efficiency can be reached below $2 / 3$ of rated torque in the whole speed range from 10 to $100 \mathrm{~Hz}$.
\end{abstract}

\section{Key words}

energy efficiency, multilevel inverter, variable speed drive, vector control, rotor flux

\section{Introduction}

The energy efficiency of electrical drives is becoming more and more important in the last years. The rapid growth in world energy prices and consumption force the electrical drive companies to develop energy recovering and saving features for electrical drives systems. In Germany, electrical drives have an energy saving potential of about $27 \mathrm{TWh}$, which can be realised by high-efficiency motors, speed control and energy recovery. An additional part of about 2 TWh can be reached with induction motors by a combination of multilevel inverter and variable rotor flux control, which is the content of this paper.

Multilevel inverter topologies are well established for medium voltage applications up to $10 \mathrm{kV}$. Dividing high voltage into smaller voltage steps allows the use of $3,3 \mathrm{kV}$ -
IGBT also at $10 \mathrm{kV}$ DC link voltage. The progress in research and development of low-voltage power semiconductors leads to the idea to extend the application of multilevel inverters from the medium to the low voltage range $(<1000 \mathrm{~V})$ [1]. In the low voltage range a lot of optimised switches (IGBT, MOSFET) are available [2], [3]. Therefore multilevel topologies could outperform the classical two-level inverter with fewer losses.

Another potential for efficiency improvement of induction motor drives is the vector control with variable rotor flux, if the operation point differs from the rated operation (e.g. at partial load or low speed) [4], [5]. Conventionally, the induction machine is controlled with constant rotor flux over the whole load and speed range. This reduces the motor efficiency at partial load. The idea is to pre-calculate the optimal rotor flux in order to maximize the motor efficiency for each load torque and speed.

\section{Multilevel Inverter}

The most popular topology for multilevel inverter is the neutral-point-clamped (NPC) three-level voltage source inverter, which is shown in Fig. 1.

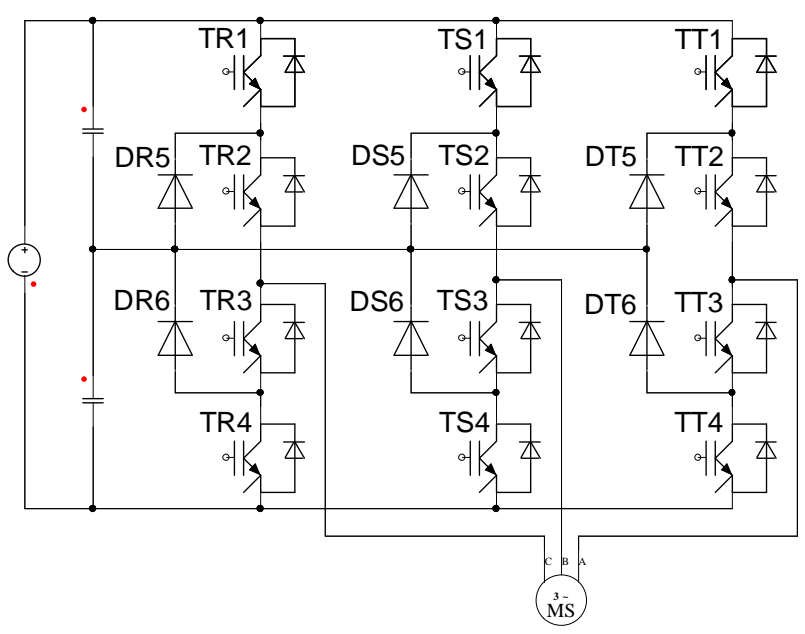

Fig. 1. Three-level NPC inverter 
This three-level inverter can be equipped with $600 \mathrm{~V}$ IGBT instead of $1200 \mathrm{~V}$-IGBT, which are used for twolevel inverter. $600 \mathrm{~V}$-IGBT have lower conduction and switching losses, therefore the three-level inverter enables an improvement of the inverter efficiency.

\section{A. Quality of output voltage and current}

The first obvious advantage of three-level inverter is the better quality of output voltage and current, which are shown in Fig. 2 and 3 for a switching frequency of $4 \mathrm{kHz}$. The voltage steps in the three-level inverter (Fig. 3) are the half of the DC link voltage. Therefore the current ripples of the three-level inverter are nearly halved in contrast to the two-level inverter (Fig. 2) at the same switching frequency [7].

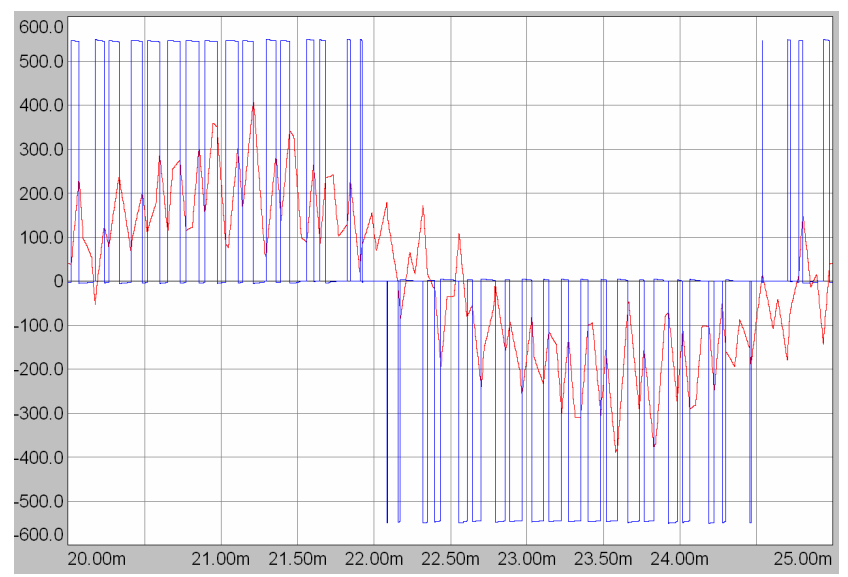

Fig. 2. Output voltage (blue) and current (red) of a two-level inverter at $4 \mathrm{kHz}$ switching frequency

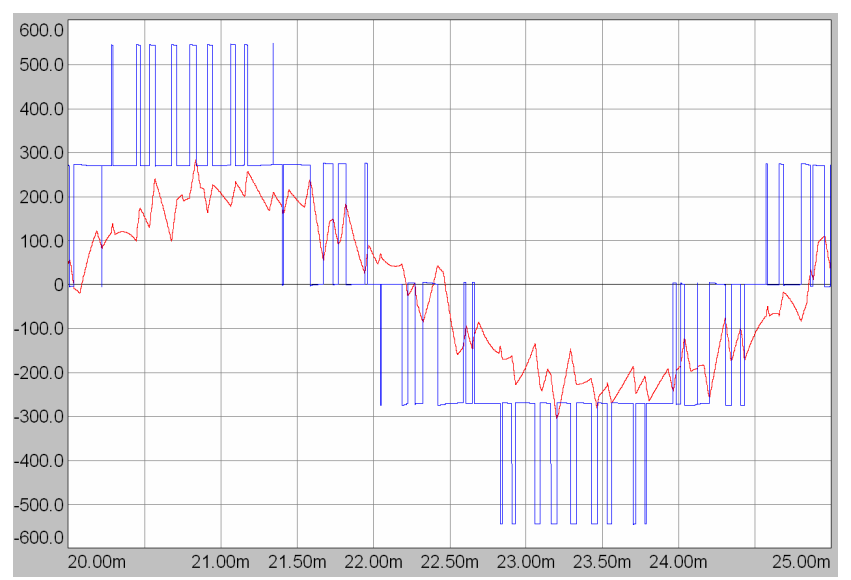

Fig. 3. Output voltage (blue) and current (red) of a three-level inverter at $4 \mathrm{kHz}$ switching frequency

The ripples of output voltage and current can be quantified by the total harmonic distortion content (THD). Fig. 4 compares the calculated THD content of two-level and three-level inverter for different motor operation points between rated load and low load. The THD of the output current strongly depends on the switching frequency and on the motor operation point. A critical situation for the output current quality is low load torque. In this case the three-level inverter also reduces the THD considerably. For example, at $4 \mathrm{kHz}$ inverter switching frequency the reduction of THD amounts $64 \%$. This reduces the harmonic power losses in the induction motor and in the motor cable.

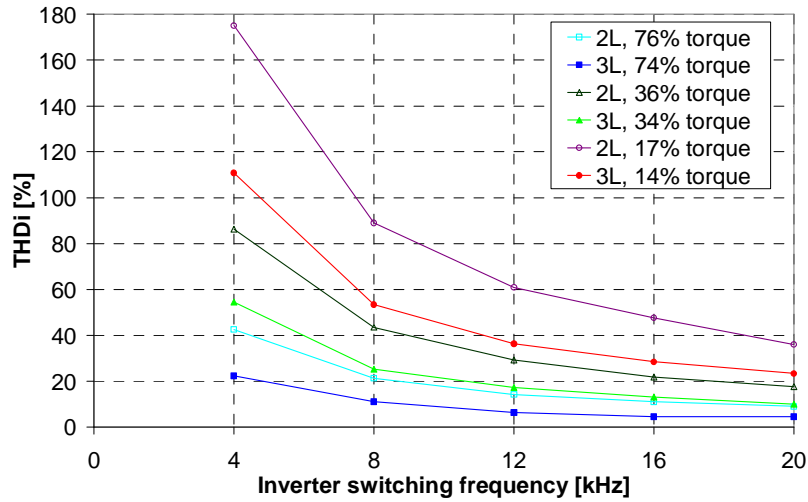

Fig. 4. THD of stator current as a function of switching frequency

\section{B. Conduction and switching losses}

The calculation of conduction and switching losses by means of the following equations is commonly used by the power semiconductor manufacturers. This method uses a linear approach for the voltage drop in the IGBT and the diode for the conduction losses. It is also assumed that the switching losses linearly depend on the current [7]. The equations only deliver good results for sinusoidal currents.

\section{1) Two-level inverter}

The conduction losses of one bridge leg can be calculated by means of the following equations. It depend on the motor current amplitude $\left(i_{1}\right)$, the modulation index $(m)$, the phase angle $\left(\varphi_{1}\right)$ and on the steady-state parameters of the power semiconductor devices.

$$
\begin{aligned}
& P_{V L T 1}=\frac{1}{2}\left(\frac{U_{C E T 0}}{\pi} \hat{i}_{1}+\frac{r_{C E}}{4} \hat{i}_{1}^{2}\right)+m \cdot \cos \varphi_{1}\left(\frac{U_{C E T 0}}{8} \hat{i}_{1}+\frac{r_{C E}}{3 \pi} \hat{i}_{1}^{2}\right) \\
& P_{V L D 2}=\frac{1}{2}\left(\frac{U_{F 0}}{\pi} \hat{i}_{1}+\frac{r_{F}}{4} \hat{i}_{1}^{2}\right)-m \cdot \cos \varphi_{1}\left(\frac{U_{F 0}}{8} \hat{i}_{1}+\frac{r_{F}}{3 \pi} \hat{i}_{1}^{2}\right)
\end{aligned}
$$

For the switching losses of one bridge leg the equations (3) and (4) can be used. The switching energies $\mathrm{E}_{\mathrm{onT}}, \mathrm{E}_{\text {offT }}$ and $\mathrm{E}_{\text {offD }}$ depend on the DC link voltage and the amplitude of the motor current. In general, a linear dependence on the motor current is assumed.

$$
\begin{aligned}
& P_{V S T 1}=\frac{1}{\pi} \cdot f_{p} \cdot\left[E_{\text {onT }}\left(\hat{i_{1}}, U_{d}\right)+E_{\text {offT }}\left(\hat{i_{1}}, U_{d}\right)\right] \\
& P_{V S D 2}=\frac{1}{\pi} \cdot f_{p} \cdot E_{\text {offD }}\left(\hat{i_{1}}, U_{d}\right)
\end{aligned}
$$

\section{2) Three-level inverter}

The conduction losses of one bridge leg can be calculated by means of the following equations [6].

$$
\begin{aligned}
P_{V L T 1 / 4} & =U_{C E T 0} \hat{i}_{1} \frac{m}{4 \pi}\left[\sin \left|\varphi_{1}\right|+\left(\pi-\left|\varphi_{1}\right|\right) \cos \varphi_{1}\right] \\
& +r_{C E} \hat{i}_{1}^{2} \frac{m}{4 \pi}\left[1+\frac{4}{3} \cos \varphi_{1}+\frac{1}{3} \cos 2 \varphi_{1}\right] \\
P_{V L T 2 / 3} & =U_{C E T 0} \hat{i}_{1}\left\{\frac{1}{\pi}-\frac{m}{4 \pi}\left[\sin \left|\varphi_{1}\right|-\left|\varphi_{1}\right| \cos \varphi_{1}\right]\right\} \\
& +r_{C E} \hat{i}_{1}^{2}\left\{\frac{1}{4}-\frac{m}{4 \pi}\left[1-\frac{4}{3} \cos \varphi_{1}+\frac{1}{3} \cos 2 \varphi_{1}\right]\right\}
\end{aligned}
$$




$$
\begin{aligned}
P_{V L D 1 / 2 / 3 / 4} & =U_{F 0} \hat{i_{1}} \frac{m}{4 \pi}\left[\sin \left|\varphi_{1}\right|-\left|\varphi_{1}\right| \cos \varphi_{1}\right] \\
& +r_{F} \hat{i}_{1}^{2} \frac{m}{4 \pi}\left[1-\frac{4}{3} \cos \varphi_{1}+\frac{1}{3} \cos 2 \varphi_{1}\right] \\
P_{V L D 5 / 6}= & U_{F 0} \hat{i_{1}}\left\{\frac{1}{\pi}-\frac{m}{4}\left[\cos \varphi_{1}+\frac{2}{\pi} \sin \left|\varphi_{1}\right|-\frac{2}{\pi}\left|\varphi_{1}\right| \cos \varphi_{1}\right]\right\} \\
+ & r_{F} \hat{i}_{1}^{2}\left\{\frac{1}{4}-\frac{m}{2 \pi}\left[1+\frac{1}{3} \cos 2 \varphi_{1}\right]\right\}
\end{aligned}
$$

For the switching losses of one bridge leg the equations (9) to (12) can be used. Each IGBT of the three-level inverter is fired only during one half of the period. That means, two-level and three-level inverters have the same number of switching events. However, the switching energies of the three-level inverter are lower and therefore the overall switching losses.

$$
\begin{aligned}
& P_{V S T 1 / 4}=\frac{1}{2 \pi} f_{p}\left[E_{\text {onT }}\left(\hat{i_{1}}, \frac{U_{d}}{2}\right)+E_{\text {offT }}\left(\hat{i_{1}}, \frac{U_{d}}{2}\right)\right]\left(1+\cos \varphi_{1}\right) \\
& P_{V S T 2 / 3}=\frac{1}{2 \pi} f_{p}\left[E_{\text {onT }}\left(\hat{i_{1}}, \frac{U_{d}}{2}\right)+E_{\text {offT }}\left(\hat{i_{1}}, \frac{U_{d}}{2}\right)\right]\left(1-\cos \varphi_{1}\right) \\
& P_{V S D 1 / 2 / 3 / 4}=\frac{1}{2 \pi} \cdot f_{p} \cdot E_{\text {offD }}\left(\hat{i_{1}}, \frac{U_{d}}{2}\right)\left(1-\cos \varphi_{1}\right) \\
& P_{V S D 5 / 6}=\frac{1}{\pi} \cdot f_{p} \cdot E_{o f f D}\left(\hat{i_{1}}, \frac{U_{d}}{2}\right)
\end{aligned}
$$

The calculation of conduction and switching losses was done for $1200 \mathrm{~V}$-IGBT (2L) and $600 \mathrm{~V}$-IGBT (3L) with the parameters in Table I [7]. The $600 \mathrm{~V}$-IGBT is a special module which is designed for three-level NPC inverters. Additionally, the power losses are simulated by means of a complete model of the drive system.

Table I. - IGBT parameters for calculation of conduction and switching losses

\begin{tabular}{|c|c|c|c|c|c|c|c|}
\hline & $\begin{array}{c}\mathrm{U}_{\mathrm{CET} 0} \\
\mathrm{~V}\end{array}$ & $\begin{array}{c}\mathrm{r}_{\mathrm{CE}} \\
\mathrm{m} \Omega\end{array}$ & $\begin{array}{c}\mathrm{U}_{\mathrm{F} 0} \\
\mathrm{~V}\end{array}$ & $\begin{array}{c}\mathrm{r}_{\mathrm{F}} \\
\mathrm{m} \Omega\end{array}$ & $\begin{array}{c}\mathrm{E}_{\text {onT }} \\
\mathrm{mWs}\end{array}$ & $\begin{array}{c}\mathrm{E}_{\text {offT }} \\
\mathrm{mWs}\end{array}$ & $\begin{array}{c}\mathrm{E}_{\text {offD }} \\
\mathrm{mWs}\end{array}$ \\
\hline 2L & 0,9 & 12 & 0,9 & 7 & 10 & 9 & 5,5 \\
\hline 3L & 0,7 & 6,5 & 0,9 & 4 & 2,7 & 5,9 & 2,4 \\
\hline
\end{tabular}

The two methods for estimation of conduction and switching losses (calculation, simulation) are applied to different motor operation points $(35 \mathrm{~kW}, 16 \mathrm{~kW})$. The results are shown in Fig. 5 and 6. The diagrams show the total (conduction and switching) losses of one inverter leg for the two-level and three-level inverter as a function of switching frequency.

In general, the simulated losses are higher than the calculated losses. At rated power (Fig. 5) the deviation is smaller than $5 \%$. At $4 \mathrm{kHz}$ inverter switching frequency the losses of the two-level are nearly equal to the threelevel inverter (break-even). However at $20 \mathrm{kHz}$ the power semiconductor losses of the three-level inverter are $38 \%$ lower compared to the two-level inverter. The optimal recommended switching frequency of three-level inverter is between $16 \mathrm{kHz}$ (above the audible frequency) and $30 \mathrm{kHz}$.
At medium power (Fig. 6) the difference between simulated and calculated losses increases, but only for the two-level inverter. In the three-level inverter the deviation between simulation and calculation is also small. At $20 \mathrm{kHz}$ switching frequency the power semiconductor losses of the three-level inverter are $48 \%$ lower compared to the two-level inverter.

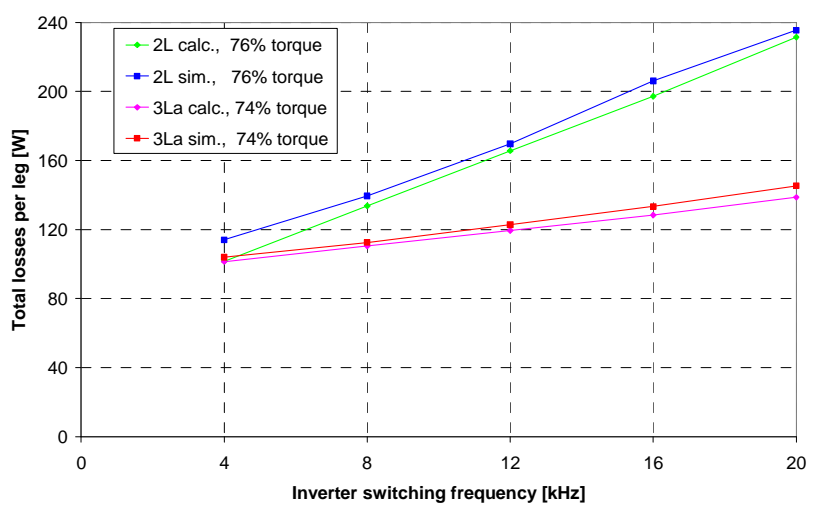

Fig. 5. Total losses per leg as a function of switching frequency at rated motor torque

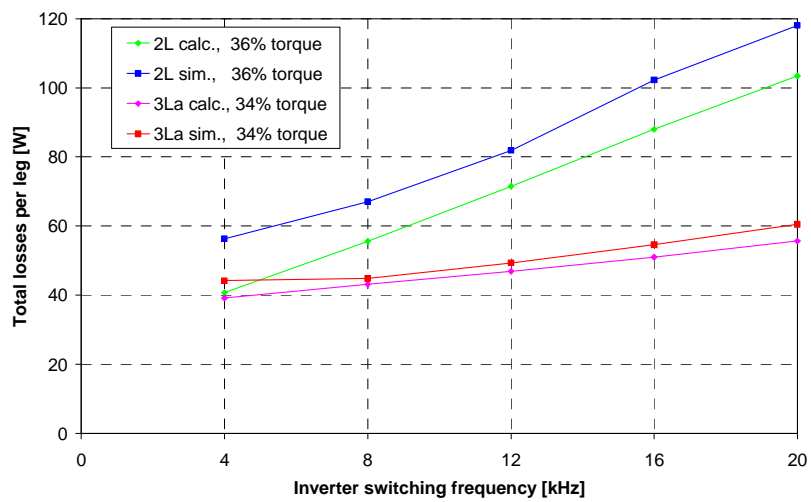

Fig. 6. Total losses per leg as a function of switching frequency at medium motor torque

\section{Variable rotor flux control}

The second part of energy saving is the variable rotor flux control of induction motors. Conventionally, the induction motor is controlled with constant rotor flux over the whole load and speed range. At rated operation point this leads to maximum efficiency, however constant rotor flux reduces the motor efficiency at partial load. The motor efficiency is based on the power losses, which are shown in Fig. 7 for a self-cooled induction motor.

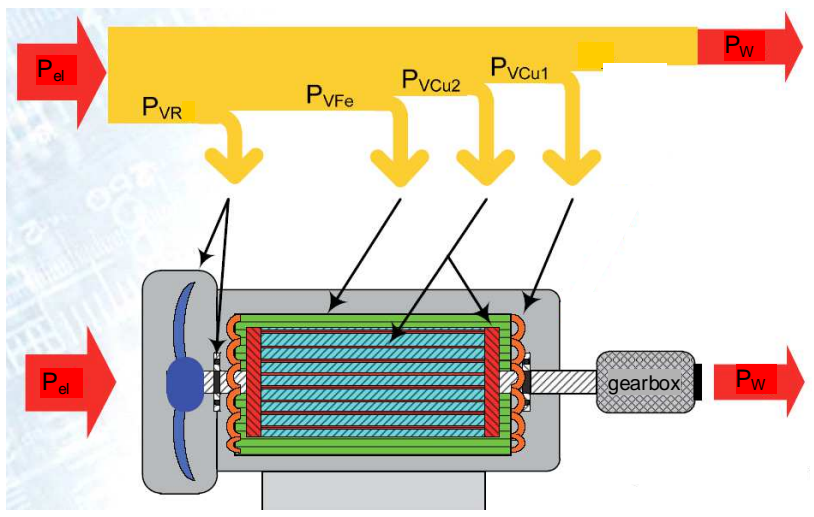

Fig. 7. Power flow of a self -cooled induction motor 


\section{A. Power losses calculation}

The steady-state model is based on the well known equivalent electric circuit of the induction machine (Fig. 8). It contains the stator and rotor resistances $\left(\mathrm{R}_{1}\right.$, $\left.\mathrm{R}_{2}\right)$, the stator and rotor leakage inductances $\left(\mathrm{L}_{1 \sigma}, \mathrm{L}_{2 \sigma}\right)$, the main inductance $\left(\mathrm{L}_{\mathrm{h}}\right)$ and the iron loss resistance $\left(\mathrm{R}_{\mathrm{Fe}}\right)$.

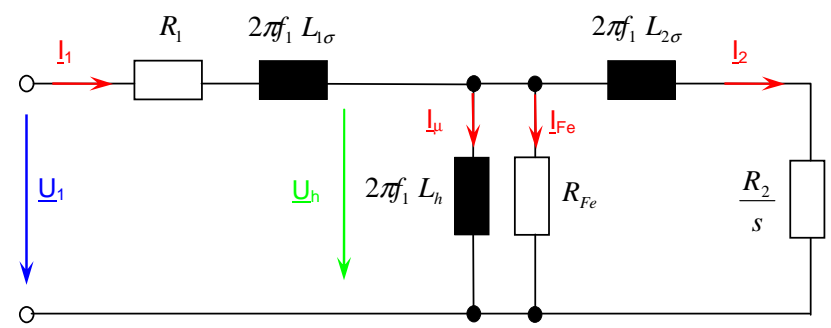

Fig. 8. Equivalent electric circuit of the induction machine

Some of these parameters are not constant. For instance, the non-linearity of the main inductance as function of the rotor flux (magnetizing curve) is shown in Fig. 9.

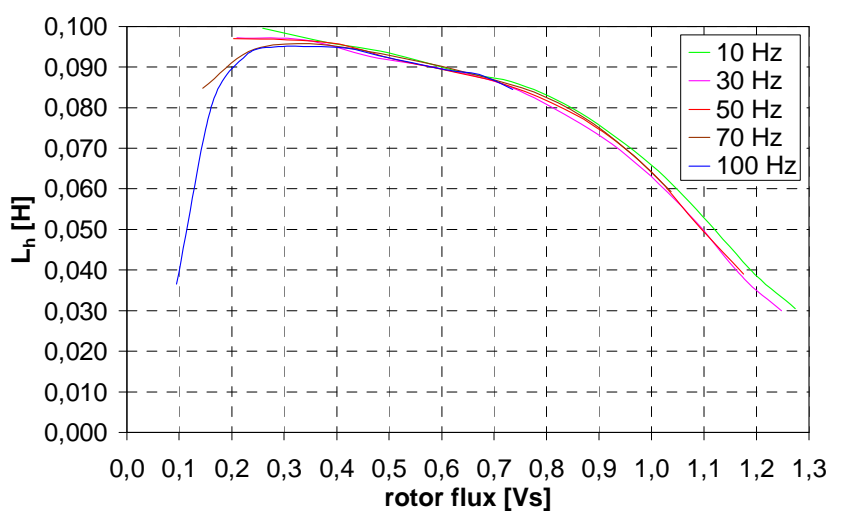

Fig. 9. Main inductance as function of rotor flux and stator frequency

For the calculation of the efficiency in the motor as well as generator operation mode the following equations are used [8], where $\mathrm{M}_{\mathrm{W}}$ is the mechanical shaft torque. The windage and friction losses are also included, which are proportional to the square of the mechanical speed.

$\begin{array}{ll} & L_{1}=L_{h}+L_{1 \sigma} \\ & L_{2}=L_{h}+L_{2 \sigma}\end{array}$

friction torque:

$$
M_{R}=\frac{30}{\pi} \cdot \frac{P_{V R 0}}{n_{0}}
$$

air gap torque:

$$
M_{\sigma}=M_{W}+M_{R}
$$

stator copper losses:

$$
P_{V C u 1}=3 R_{1}\left[\begin{array}{l}
\left(\frac{\sqrt{2} L_{2} M_{\sigma}}{3 z_{p} L_{h} \hat{\Psi}_{\sigma}}\right)^{2}+\frac{4 \pi f_{1} M_{\sigma}}{3 z_{p} R_{F e}} \\
+\frac{\left(R_{F e} \hat{\Psi}_{\sigma}\right)^{2}+\left(2 \pi f_{1} L_{h} \hat{\Psi}_{\sigma}\right)^{2}}{2\left(L_{h} R_{F e}\right)^{2}}
\end{array}\right]
$$

rotor copper losses: $P_{V C u 2}=3 R_{2}\left(\frac{\sqrt{2} M_{\sigma}}{3 z_{p} \hat{\Psi}_{\sigma}}\right)^{2}$

iron losses:

$$
P_{V F e}=\frac{6}{R_{F e}}\left(\pi f_{1} \hat{\Psi}_{\sigma}\right)^{2}
$$

mechanical speed: $\quad n=\frac{60 f_{1}}{z_{p}}\left(1-\frac{R_{2}}{3 \pi f_{1} z_{p} \hat{\Psi}_{\sigma}^{2}} M_{\sigma}\right)$

friction and windage losses: $P_{V R}=P_{V R 0}\left(\frac{n}{n_{0}}\right)^{2}$

air gap power: $\quad P_{\sigma}=\frac{2 \pi f_{1}}{z_{p}} M_{\sigma}$

efficiency:

$$
\begin{gathered}
\eta_{M o t o r}=\frac{P_{\sigma}-P_{V C u 2}-P_{V R}}{P_{\sigma}+P_{V C u 1}+P_{V F e}} \\
\eta_{\text {Generator }}=\frac{P_{\sigma}+P_{V C u 1}+P_{V F e}}{P_{\sigma}-P_{V C u 2}-P_{V R}}
\end{gathered}
$$

The power losses depend on the motor torque, the speed and the rotor flux. Therefore, an optimum rotor flux with which the efficiency has a maximum can be found for any motor torque and speed.

\section{B. Optimum rotor flux for maximum efficiency}

The efficiency calculation is applied to an $11 \mathrm{~kW}$ highefficiency induction motor [7] with the following nominal parameters for star connection:

$$
\begin{array}{lll}
\mathrm{P}_{\mathrm{N}}=11 \mathrm{~kW} & \mathrm{n}_{\mathrm{N}}=1475 \mathrm{~min}^{-1} & \mathrm{M}_{\mathrm{N}}=71,2 \mathrm{Nm} \\
\mathrm{U}_{\mathrm{NY}}=400 \mathrm{~V} & \mathrm{I}_{\mathrm{NY}}=21,5 \mathrm{~A} & \mathrm{PF}=0,82
\end{array}
$$

For constant motor torque the rotor flux varies between 0,1 and 1,2 Vs. The results are shown in Fig. 10 for $50 \mathrm{~Hz}$ motor frequency. Each curve for constant motor torque has a maximum, which leads to the best efficiency at this load. At rated load $(70 \mathrm{Nm})$ the rated rotor flux $(0,96 \mathrm{Vs})$ leads to the maximum efficiency. However, at low load the rotor flux has to be reduced in order to improve the efficiency. For example at the motor torque $2 \mathrm{Nm}$, the efficiency can be improved from $41 \%$ to $76 \%$ if the flux is reduced to $0,21 \mathrm{Vs}$.

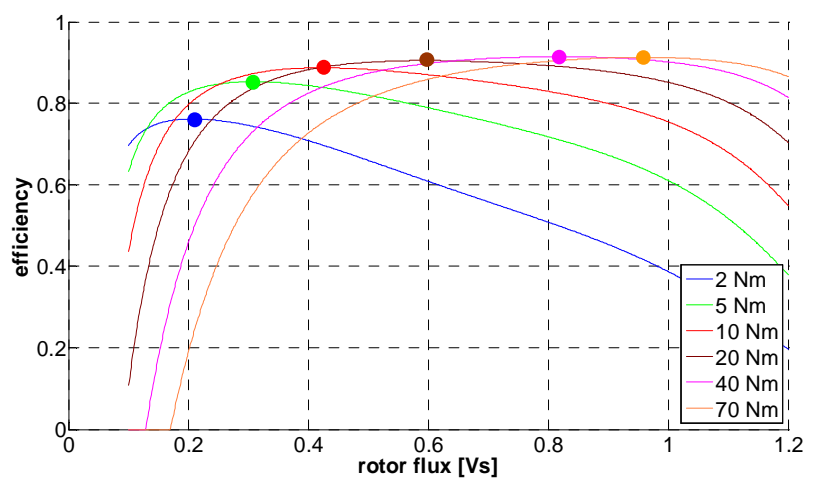

Fig. 10. Efficiency as a function of rotor flux for different motor torques at $50 \mathrm{~Hz}$ motor frequency 
Starting from Fig. 10 all efficiency maxima are detected and drawn into a 3D diagram as function of motor torque and frequency (Fig. 11). The optimum rotor flux is a monotone increasing function of the motor torque and depends on the motor frequency. At higher motor frequencies $(>50 \mathrm{~Hz})$ the motor operates in fieldweakening area and therefore the motor torque has to be reduced. At low frequencies $(10 \mathrm{~Hz})$ the optimum rotor flux can be even higher than the rated flux. This leads to an efficiency improvement at high torque. In this case the maximum efficiency occurs in the range of magnetic saturation.

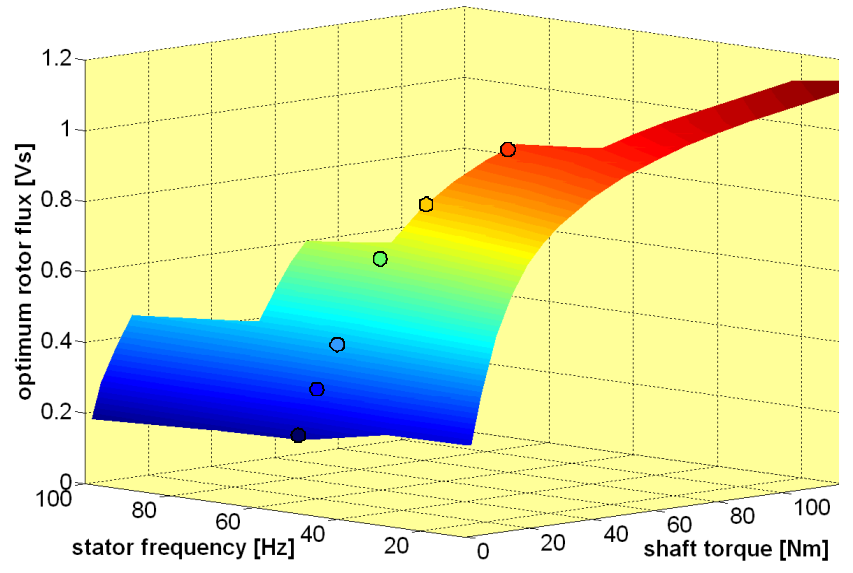

Fig. 11. Optimum rotor flux as a function of motor torque and frequency

\section{Maximum efficiency operation}

The following diagrams show the results for steady-state operation of an $11 \mathrm{~kW}$ high-efficiency induction motor at optimum rotor flux [8]. The maximum efficiency operation is compared to the commonly used constant rotor flux operation. The dots in the diagrams mark the corresponding measurement results. The $\Delta$ eff-curve (difference between constant and optimum rotor flux) in Fig. 12 shows a good accordance between calculation and measurement. The efficiency can be improved in the range below $2 / 3$ of the rated load. The maximum improvement at small motor torque reaches $35 \%$ in motor and $45 \%$ in generator mode. The average value of the efficiency improvement between no load and rated load is $4,5 \%$ in motor and 6,0 \% in generator mode. Additional advantages are the great increase in the power factor (Fig. 13) and the reduction of stator current consumption (Fig. 14).

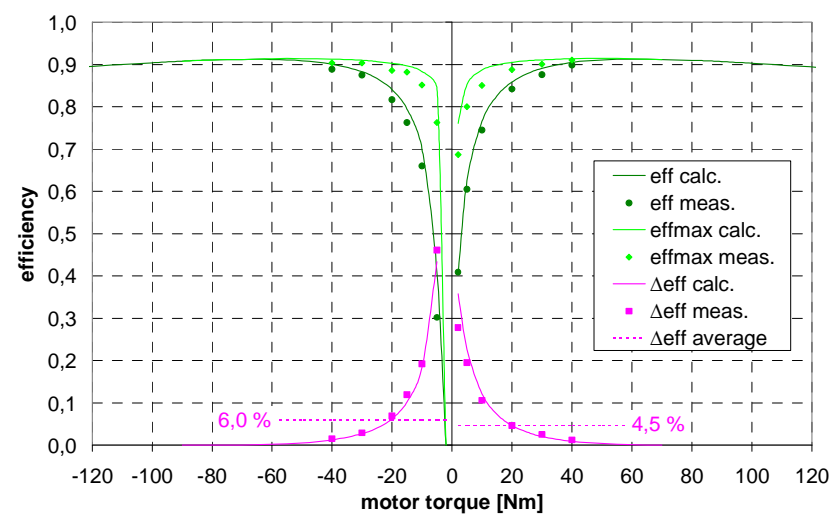

Fig. 12. Efficiency for constant and optimized rotor flux at $50 \mathrm{~Hz}$ stator frequency

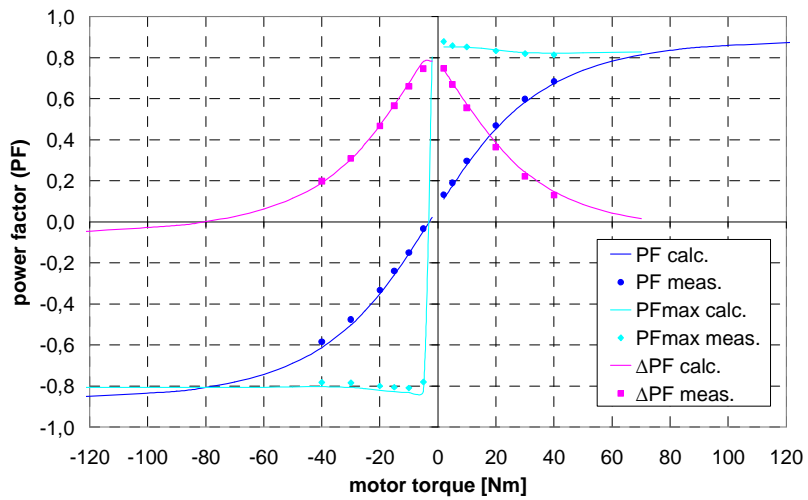

Fig. 13. Power factor for constant and optimized rotor flux at $50 \mathrm{~Hz}$ stator frequency

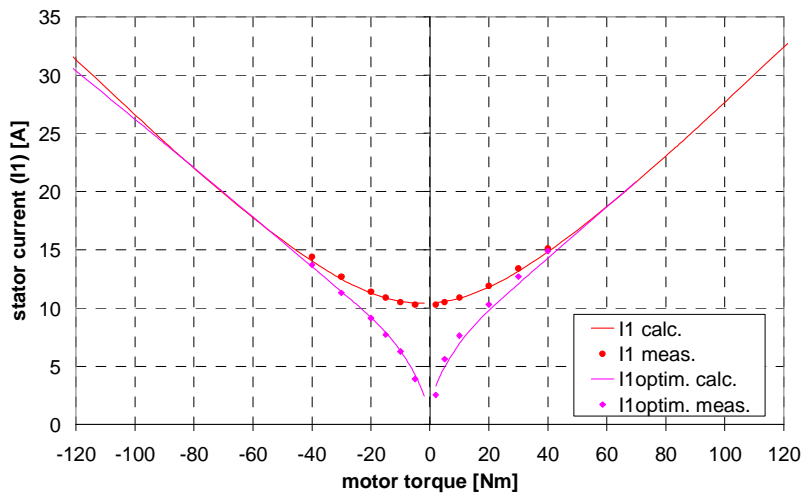

Fig. 14. Stator current for constant and optimized rotor flux at $50 \mathrm{~Hz}$ stator frequency

\section{Space vector control with optimum rotor flux}

The control principle for high dynamic requirements is space vector control (Fig. 15). The 3D diagram in Fig. 11 is implemented as reference value for the rotor flux to realize energy-efficient operation at any motor torque and speed. The variable rotor flux affects the main inductance and the rotor time constant. Therefore the parameters of the flux and speed controllers have to be adapted to the variable flux continuously.

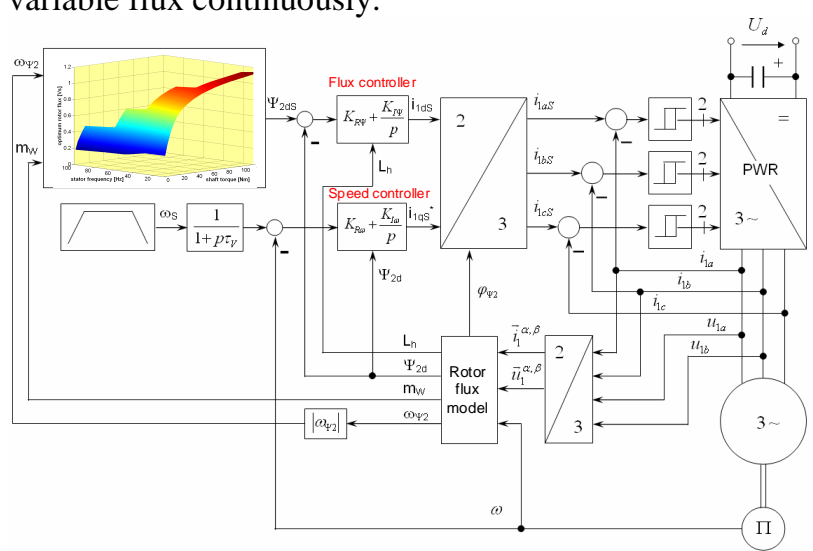

Fig. 15. Space vector control with optimum rotor flux for maximum efficiency

The dynamic behaviour of the drive is shown in Fig. 16 and 17 for a typical industrial motion cycle. The speed changes from stand-still to nominal speed and return. At $1,8 \mathrm{sec}$. the load changes from no load to nominal load and at 2,6 sec. to $15 \%$ of nominal load. Fig. 16 shows the rotor flux $\left(\Psi_{2 \mathrm{~d}}\right)$. At no load and small load the rotor flux is reduced in contrast to the constant flux control 
mode. The reduced rotor flux causes lower total losses (Fig. 17). However, changes in speed and load lead to higher transient losses. Nevertheless, the performance of the drive is quite good. The rotor flux varies so that the motor is running at every time in the energy-efficient mode. The dynamic behaviour during speed and load variations has nearly the same quality as with constant rotor flux.

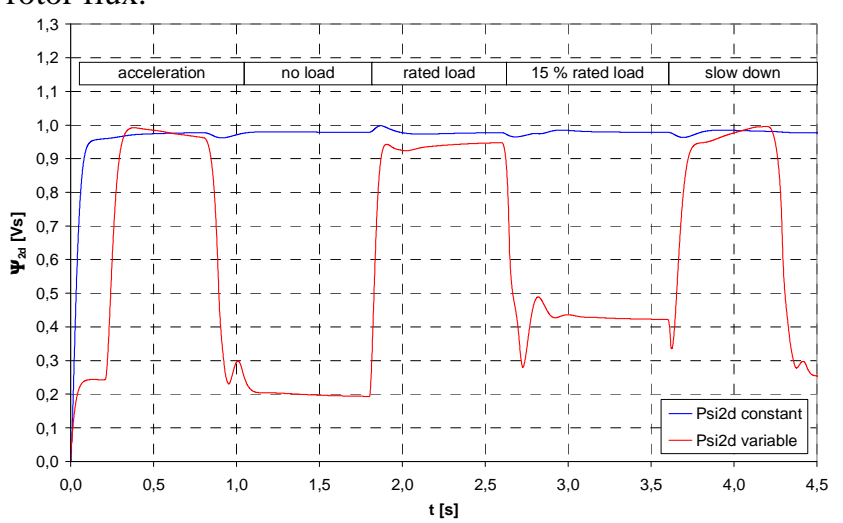

Fig. 16. Dynamic performance of the rotor flux in the energyefficient control mode

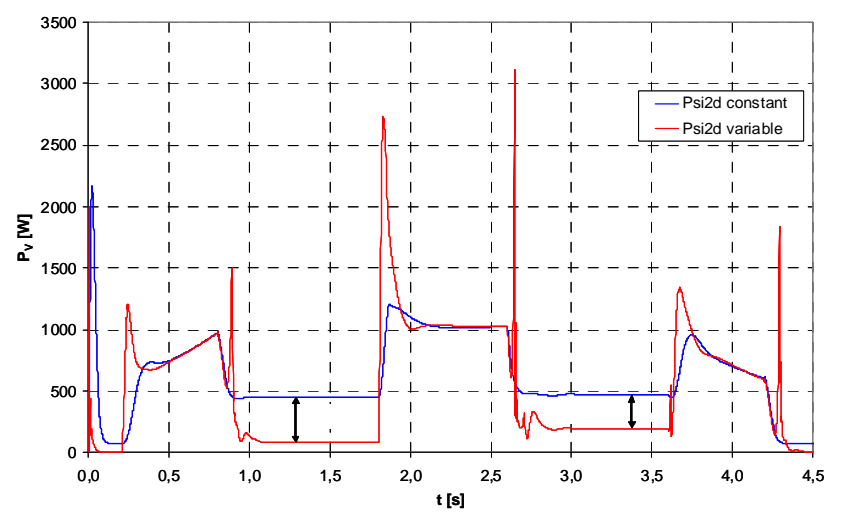

Fig. 17 Dynamic performance of the total losses in the energyefficient control mode

Table II compares the energy losses between constant and variable rotor flux for the complete motion cycle [8]. The last line of the table contains the difference of energy losses. The negative sign means that the energy losses at variable rotor flux are lower (energy saving). The greatest energy saving potential occurs during steady-state operation at no-load and small load (15\% of nominal load). In both cases the rotor flux is low and therefore the efficiency increases. During load change (rated load) and braking (slow down) the energy losses are a little bit higher compared to constant flux. The overall energy saving potential of this motion cycle amounts $-17 \%$. The longer the no-load and small load stages the higher the energy saving potential.

Table II. - Energy losses with constant and variable rotor flux

\begin{tabular}{|l|c|c|c|c|c|c|}
\hline & $\begin{array}{c}\text { accele- } \\
\text { ration }\end{array}$ & $\begin{array}{c}\text { no } \\
\text { load }\end{array}$ & $\begin{array}{c}\text { rated } \\
\text { load }\end{array}$ & $\begin{array}{c}15 \% \\
\text { rated } \\
\text { load }\end{array}$ & $\begin{array}{c}\text { slow } \\
\text { down }\end{array}$ & sum \\
\hline $\begin{array}{l}\text { constant } \\
\text { flux }\end{array}$ & $\begin{array}{c}628 \\
\mathrm{Ws}\end{array}$ & $\begin{array}{c}365 \\
\mathrm{Ws}\end{array}$ & $\begin{array}{c}825 \\
\mathrm{Ws}\end{array}$ & $\begin{array}{c}487 \\
\mathrm{Ws}\end{array}$ & $\begin{array}{c}489 \\
\mathrm{Ws}\end{array}$ & $\begin{array}{c}2794 \\
\mathrm{Ws}\end{array}$ \\
\hline $\begin{array}{l}\text { variable } \\
\text { flux }\end{array}$ & $\begin{array}{c}577 \\
\mathrm{Ws}\end{array}$ & $\begin{array}{c}67 \\
\mathrm{Ws}\end{array}$ & $\begin{array}{c}915 \\
\mathrm{Ws}\end{array}$ & $\begin{array}{c}249 \\
\mathrm{Ws}\end{array}$ & $\begin{array}{c}522 \\
\mathrm{Ws}\end{array}$ & $\begin{array}{c}2330 \\
\mathrm{Ws}\end{array}$ \\
\hline $\begin{array}{l}\text { energy } \\
\text { saving }\end{array}$ & $-8 \%$ & $-82 \%$ & $+11 \%$ & $-49 \%$ & $+7 \%$ & $-17 \%$ \\
\hline
\end{tabular}

\section{Conclusion}

In order to save energy with induction motor drives a combination of a new topology for the frequency inverter and the control with variable rotor flux is investigated.

The three-level frequency inverter can be equipped with $600 \mathrm{~V}$-IGBT instead of $1200 \mathrm{~V}$-IGBT for the two-level inverter. The conduction and switching losses of the three-level inverter are lower compared with the twolevel inverter. For example, at $20 \mathrm{kHz}$ switching frequency the power semiconductor losses at rated load are $38 \%$ lower and at medium load are $48 \%$ lower. Therefore, new wide-bandgap semiconductors ( $\mathrm{SiC}$, $\mathrm{GaN}$ ) with low blocking voltage have the potential to reduce the conduction and switching losses in multilevel inverters. This would lead to a reduction of cooling effort and to smaller inverter size. Moreover, the sine filter at the inverter output can be chosen smaller which is accompanied by lower power losses inside the filter. The application of multilevel inverters can make a contribution to efficiency improvement in electrical drives.

The variable rotor flux control has also a potential for energy saving in induction motors. The optimum rotor flux is load-dependent and has to be reduced at low load. The energy saving potential is in the range from low to medium load and in the whole speed range from 10 to $100 \mathrm{~Hz}$ motor frequency. The optimum rotor flux curve can be used as reference value in the space vector control. The commonly used space vector control has to be extended by a variable rotor flux reference value and adaptive flux and speed controllers. The dynamic behaviour of the energy-efficient speed-controlled drive with variable rotor flux is quite excellent.

\section{References}

[1] Koszescha, J., Advanced multilevel topologies: A technological breakthrough? Bodos Power Systems, pp. 14, 2010.

[2] Honsberg, M. \& Radke, T., 3-level IGBT modules with trench gate IGBT and their thermal analysis in UPS, PFC and PV operation modes. Proceedings of the European Conference on Power Electronics and Applications, 2009.

[3] Di Lella, M. \& Ramin, R., IGBTs for 3-level inverters. Bodos Power Systems, pp. 22-24, 2008.

[4] Kioskeridis, I. \& Margaris, N., Loss minimization in scalarcontrolled induction motor drives with search controllers. IEEE Transactions on Power Electronics, Vol. 11, No. 2, pp. 213-220, 1996.

[5] Chen, S. \& Nian Yeh, S., Optimal efficiency analysis of induction motors fed by variable-voltage and variablefrequency source. IEEE Transactions on Energy Conversion, Vol. 7, No. 3, pp. 537-543, 1992.

[6] Tomta, G. \& Nilsen, R., Analytical equations for three level NPC converters. Proceedings of the European Conference on Power Electronics and Applications, 2001.

[7] Mecke, R., Efficient induction motor drive with multilevel inverter and variable rotor flux. Proceedings of the International Symposium on Industrial Electronics, 2017.

[8] Mecke, R., Energy-efficiency control of induction machines with variable rotor flux. Proceedings of the European Conference on Power Electronics and Applications, 2013. 